\title{
DEVELOPMENT MODELOF TRADITIONAL GAME (GONTENG) AS PHYSICAL EDUCATION LEARNING IN CHARACTER BUILDING FOR UPPER CLASS ELEMENTARY SCHOOL STUDENTS
}

\section{Puput Widodo, Ibnu Prasetyo Widiyono, Yogi Ferdy Iriawan}

Universitas Ma'arif Nahdlatul Ulama Kebumen puputwidodo72@gmail.com

\section{Article History}

accepted 30/09/2018

approved 12/10/2018

published 30/10/2018

\section{Keywords}

models, traditional games, characters, phsical

\begin{abstract}
The study was conducted through two stages: (1) predevelopment stage, which includes; (a) review of relevant literature and research, and (b) field studies, (2) the development stage,which includes; (a) drafting, (b) validation expert, (c) testing of small-scale models, (d) testing largescale models, and (e) of the final product.The small-scale tryout was conducted by involving 30 students of upper grades. The large-scale tryout was conducted by involving 130 students of upper grades. The data collecting instruments were an interview guideline, a questionnaire to assess characters of traditional games, a questionnaire to assess the traditional game development, a questionnaire for the assessment by the media expert, and a questionnaire for the evaluation by students. Based on the assessment by experts andteachers of physical, sports, and health education, it was concluded that the developed models of traditional games were effective to be used in the learning for the students of upper grades.
\end{abstract}

Social, Humanities, and Education Studies (SHEs): Conference Series https://jurnal.uns.ac.id/shes
p-ISSN 2620-9284

e-ISSN 2620-9292 


\section{PENDAHULUAN}

Bermain merupakan kegiatan ataupun aktivitas wajib yang dilakukan anakanak untuk mengenal lingkungan sekitar, bermain juga sering dilakukan orang dewasa untuk melepaskan kejenuhan dan menghilangkan stres. Bermain (play) adalah setiap kegiatan yang dilakukan untuk kesenangan yang ditimbulkannya, tanpa mempertimbangkan hasil akhir. Menurut Suharjana (2011) bermain pada hakikatnya merupakan salah satu kebutuhan hidup bagi anak. Dalam kehidupan anak, bermain merupakan latihan-latihan yang dilakukan agar anak menjadi manusia dewasa yang lebih banyak mendapatkan kesempatan untuk melatih potensi-potensi yang ada pada dirinya, oleh karena itu bermain tidak dapat dipisahkan dari kehidupan anak itu sendiri. Menurut Thompson (Sridadi, 2009) bermain berarti menyediakan kesepampatan untuk memperoleh pengalaman belajar yang menyenangkan. Adapun keuntungan yang diperoleh dari aktivitas bermain menurut Mutohir (Sridadi, 2009) adalah (a) membuang ekstra energi, (b) mengoptimalkan pertumbuhan seluruh bagian tubuh seperti tulang, otot, dan organ-organ, (c) meningkatkan nafsu makan anak, (d) anak belajar mengontrol diri, (e) berkembangnya berbagai ketrampilan yang akan berguna sepanjang hidupnya, (f) meningkatkan gaya kreatifitas, (g) mendapatkan kesempatan belajar untuk bergaul dengan anak lainnya, (j) kesempatan untuk menjadi pihak yang kalah atau yang menang dalam bermain, (k) kesempatan untuk belajar mengikuti aturan-aturan, dan (I) dapat mengembangkan kemampuan intelektual. Dalam bermain, anak-anak selalu berperilaku diatas usia rata-ratanya, diatas perilakunya sehari-hari, dalam bermain anak dianggap 'lebih' dari dirinya sendiri. Selanjutnya dijelaskan terdapat dua ciri utama bermain, yaitu: (1) semua aktivitas representasional menciptakan situasi imajiner yang memungkinkan anak untuk menghadapi keinginankeinginan yang tidak dapat direalisasikan dalam kehidupan nyata, dan (2) bermain representasional memuat aturan-aturan berperilaku yang harus diikuti oleh anak untuk dapat menjalankan adegan bermain (Yuliani dan Sujiono, 2010).

-Permainan Tradisional

Menurut Linggar (2010) olahraga/permainan tradisional adalah jenis olahraga yang timbul berdasarkan permainan dari masing-masing suku dan etnis di Indonesia. Menurut K. Dewi, dkk (2013) tradisional merupakan suatu permainan yang mirip dengan olah raga yakni memiliki aturan main yang memberikan kesenangan, kegembiraan, dan tantangan. Berdasarkan pendapat di atas dapat disimpulkan bahwa permainan tradisional adalah aktivitas yang dilakukan tanpa paksaan, mendatangkan rasa kegembiraan, dalam suasana yang menyenangkan berdasarkan tradisi masingmasing daerah yang ada di lingkungan, dimainkan dengan menggunakan alat ataupun tidak menggunakan alat, dan dilakukan sesuai/dengan aturan yang sudah disepakati sebelum permainan dimulai, seperti peraturan, lapangan, jumlah pemain, dan lain sebagainya.

-Karakter

Secara umum karakter hanya dapat terjadi ketika dibangun. Pendikan karakter harus diutamankan dan bukan hanya dalam hanya satu pelajaran tetapi harus dilaksanakan seumur hidup. Kesuma (2011) mengungkapkan bahwa sebuah proses transportasi nilai-nilai kehidupan untuk ditumbuh kembangkan dalam kepribadian seseorang sehingga menjadi satu dalam perilaku kehidupan orang tersebut dan dapat dibangun oleh suatu kebiasaan dan latihan. Dapat disimpulkan bahwa ada beberapa karakter dasar yang perlu dibangun untuk anak-anak antara lain: kerjasama, kejujuran, disiplin, tanggung jawab, percaya diri, dan toleransi terhadap sesama/peduli sesama. -Pengembangan Permaian Tradisional

Adapun permainan tradisional yang akan dikembangkan yaitu kombinasi antara permainan gobak sodor dan bentengan (gonteng). Permainan gobak sodor dan 
bentengan merupakan permainan kombinasi dua permainan menjadi satu permainan, dengan dimodifikasi aturan permainan, bahan atau alat yang disediakan dan lapangan yang dibuat sesuai keadaan atau lingkungan sekolahan yang ada.

-Tujuan Pengembangan Model Permainan Tradisional

Tujuan dari model pengembangan permainan tradisional yaitu membangun karakter kerjasama, kejujuran, dan sportivitas siswa SD kelas atas, dan dapat meningkatkan gerak dasar psikomotor sesuai SK dan KD dalam pembelajaran penjas SD kelas atas.

-Model Pengembangan Permainan Tradisional

Adapun model pengembangan model permainan tradisional dalam penelitian ini adalah permainan gobak sodor dan bentengan, Permainan kombinasi ini peneliti memberi nama "gonteng" (gobak sodor dan bentengan). Permainan gonteng merupakan kombinasi antara permainan gobak sodor dan bentengan dengan memodifikasi peralatan dan aturan permainan.

\section{METODE}

Ada 2 tahap dalam penelitian ini, yaitu tahap pra-pengembangan dan tahap pengembangan. (a) Dalam tahap pra-pengembangan meliputi: kajian literatur/ penelitian relevan dan studi lapangan,dan (b) tahap pengembangan dibagi menjadi beberapa langkah-langkah yaitu penyusunan draft model awal pembelajaran, validasi ahli, uji coba skala kecil, uji coba skala besar, dan produk operasioanl terbatas.

-Subjek Penilitian

Subjek dalam penelitian ini yaitu siswa SD kelas atas. Adapun subjek dalam penelitian ini berjumlah 160 siswa SDN di Kecamatan Pejagoan, Kabupaten Kebumen. -Teknik dan Instrumen Pengumpulan Data

Instrumen yang digunakan untuk mengumpulkan data berupa instrumen penilaian untuk menilai produk yang telah dikembangkan dari aspek kesesuaian, aspek isi, aspek kemudahan, dan aspek rangsangan terhadap gerak siswa. Selain itu metode pengamatan dilaksanakan untuk menilai/mengetahui karakter yang diinginkan dapat tercapai atau tidak melalui kuisioner penilaian karakter.

-Analisis Data

Analisis data ini adalah wawancara, catatan lapangan, dan data-data lain. Teknik analisis data dalam penelitian ini adalah uji kelayakan dan keefektifan draf penilaian oleh ahli pembelajaran penjas, ahli media, guru dan siswa pada saat uji coba lapangan berlangsung. Uji validitas dan uji reliabilitas draf dilakukan dengan menggunakan data kuesoner untuk responden guru dan. Uji validitas dan uji reliabilitas dilakukan dengan menggunakan bantuan Microsoft Excell 2007.

\section{HASIL DAN PEMBAHASAN}

Uji coba lapangan baik skala kecil maupun besar dilaksanakan setelah mendapat validasi atau standar kelayakan dari ahli penjas. Instrumen validasi draf awal oleh ahli penjas maupun guru partisipan menggunakan instrumen angket. Adapun hasil terhadap draf awal adalah sebagai berikut:

Tabel 1. Penilaian Validasi oleh pembelajaran penjas dan guru partisipan

\begin{tabular}{|c|c|cc|c|}
\hline \multirow{2}{*}{ No } & \multirow{2}{*}{ Permainan } & \multicolumn{3}{|c|}{ Skor Penilaian } \\
\cline { 3 - 5 } & & A1 & A2 & A3 \\
\hline 1 & Gonteng & 67 & 79 & 78 \\
\hline
\end{tabular}


Tabel 2. Kategorisasi Penilaian Validasi Ahli Pembelajaran Penjas dan Guru

\begin{tabular}{|c|c|c|c|c|}
\hline \multirow{2}{*}{ Interval } & \multirow{3}{*}{ Kategori } & \multicolumn{3}{|c|}{ Nama Permainan } \\
\cline { 3 - 5 } & & $\mathrm{A} 1$ & $\mathrm{~A} 2$ & $\mathrm{~A} 3$ \\
\cline { 3 - 5 } & & $\mathrm{F}$ & $\mathrm{F}$ & $\mathrm{f}$ \\
\hline $\mathrm{X}<44$ & Kurang & - & - & - \\
\hline $44 \leq \mathrm{X}<66$ & Cukup & - & - & - \\
\hline $66 \leq \mathrm{X}$ & Baik & 67 & 79 & 78 \\
\hline
\end{tabular}

Tabel 2 menunjukkan penilaian ahli materi terhadap draf awal berdasarkan karakter. Total nilai para ahli materi terletak pada interval $66 \leq \mathrm{X}$. Jadi, penilaian para ahli materi terhadap draf awal berdasarkan karakter sebagai pembelajaran penjas bagi anak sekolah dasar kelas atas berkategori baik.

-Uji Coba Skala Kecil

Uji coba skala kecil dilakukan pada anak kelas atas dengan jumlah 30 anak. Pelaksanaan uji coba skala kecil direkam dalam DVD kemudian diobservasi oleh observer. Data yang diperoleh dari observer berupa: data hasil observasi penilaian karakter, data hasil observasi, data hasil observasi keefektifan, data hasil penilian observasi ahli media, data hasil evaluasi siswa dan saran perbaikan.

Tabel 3. Hasil Uji Coba Skala Kecil

\begin{tabular}{|c|c|}
\hline Penilaian & Kategori \\
\hline Guru Partisipan & Baik \\
\hline Ahli Media & Baik \\
\hline Siswa & Baik \\
\hline
\end{tabular}

Berdasarkan kategori penilaian semua item hasil uji coba skala kecil berkategori baik. Adapun hasilnya disajikan sebagai berikut:

Tabel 4. Hasil Uji Coba Karakter Skala Kecil

\begin{tabular}{|c|c|c|c|}
\hline Penilaian & TM & M & SM \\
\hline Guru Partisipan & 2 & 4 & 3 \\
\hline
\end{tabular}

Hasil penilaian karakter pada guru penjas pada uji coba skala kecil mendapat total nilai TM: 2, M: 4, SM: 3 poin dengan presentase TM: 22,2\%, M: 44,4\%, dan SM: 33,4\%. Berdasarkan penilaian guru penjas, terlihat bahwa total penilaian karakter dapat dikatakan baik dengan katagori memenuhi $44,4 \%$ dan sangat memenuhi 33,4\%.

-Uji Coba Skala Besar

Uji coba skala besar dilaksanakan di 5 sekolah dasar dengan jumlah 130 siswa Pelaksanaan uji coba skala besar direkam dalam DVD kemudian diobservasi oleh observer.

Tabel 5. Hasil Uji Coba Skala Besar

\begin{tabular}{|c|c|}
\hline Penilaian & Kategori \\
\hline Guru Partisipan & Baik \\
\hline Ahli Media & Baik \\
\hline Siswa & Baik \\
\hline
\end{tabular}

Berdasarkan kategori penilaian semua item hasil uji coba skala besar berkategori baik. Hasil penilaian karakter pada uji coba skala besar disajikan sebagai berikut:

Tabel 6. Hasil Uji Coba Karakter Skala Besa
\begin{tabular}{|c|c|c|c|}
\hline Penilaian & TM & M & SM \\
\hline $\begin{array}{c}\text { Guru } \\
\text { Partisipan }\end{array}$ & 0 & 17 & 33 \\
\hline
\end{tabular}

Hasil penilaian karakter pada ahli materi dan guru penjas pada uji coba skala besar mendapat total nilai TM : 0, M : 74, SM : 136 poin dengan presentase TM : 0\%, M 
: 66\%, dan SM : 34\%. Jadi dapat di simpulkan bahwa model dapat membangun karakter dengan hasil sebagian besar sangat baik/memenuhi kriteria yang diinginkan.

-Uji Efektifitas

Uji efektifitas dilaksanakan di SDN Aditirto dengan jumlah siswa 30 dengan 6 kali perlakuan. Pelaksanaan uji efektifitas dilakukan dengan menguji dua kategori yaitu karakter dan psikomotor.

Tabel 7. Hasil Uji Efektivitas Produk

\begin{tabular}{|c|l|c|c|}
\hline UjiEfektifitas & Penilaian & HasilPretest & HasilPostest \\
\hline Karakter & Siswa & 602 & 712 \\
\hline & Guru & 202 & 245 \\
\hline Psikomotor & Guru & 209,5 & 250 \\
\hline
\end{tabular}

Data Persamaan 1 siswa

Data di atas kemudian dimasukan ke dalam tabel gain ternormalisasi dengan rumus persamaan 1 sebagai berikut:

$$
(\mathrm{g})=\frac{(S f-S i)}{(\operatorname{Smax}-S i)}
$$

Keterangan:

$\langle\mathrm{g}\rangle=$ rata-rata gain ternormalisasi

$\langle\mathrm{Sf}\rangle=$ rata-rata nilai tes akhir (post-test)

$\langle\mathrm{Si}\rangle=$ rata-rata nilai tes awal (pre-test)

Smax $=$ Nilai skor maksimal

$$
\text { (g) }=\frac{(23,7-20,1)}{(32-20,1)}=0,302
$$

Hasil per perhitungan diinterpretasikan menggunakan indeks gain $\langle\mathrm{g}\rangle$, menurut klasifikasi oleh Hake ditunjukkan pada Tabel 61 berikut ini.

Tabel 8. Nilai Indeks Gain Ternormalisasi dan Klasifikasinya

\begin{tabular}{|c|c|}
\hline Indeks Gain Ternormalisasi & Klasifikasi \\
\hline $\mathbf{( g )} \geq \mathbf{0 , 7 0}$ & Tinggi \\
\hline $\mathbf{0 , 3 0} \leq \mathbf{0 , 7 0}$ & Sedang \\
\hline$\leq \mathbf{0 , 3 0}$ & Rendah \\
\hline
\end{tabular}

Dengan melihat tabel Indek gain maka dapat disimpulkan bahwa hasil uji efektifitas nilai karakter mendapatkan nilai 0,302 terletak pada interval $0,30 \leq 0,70$ dengan klasifikasi sedang, dengan kata lain uji efektivitas dikatakan efektif.

Data Persamaan 1 guru

Data di atas kemudian dimasukan ke dalam tabel gain ternormalisasi dengan rumus persamaan 1 sebagai berikut:

$$
\text { (g) }=\frac{(S f-S i)}{(S m a x-S i)}
$$

Tabel 9. Nilai Indeks Gain Ternormalisasi dan Klasifikasinya

\begin{tabular}{|c|c|}
\hline Indeks Gain Ternormalisasi & Klasifikasi \\
\hline $\mathbf{( g )} \geq \mathbf{0 , 7 0}$ & Tinggi \\
\hline $\mathbf{0 , 3 0} \leq \mathbf{0 , 7 0}$ & Sedang \\
\hline$\leq \mathbf{0 , 3 0}$ & Rendah \\
\hline
\end{tabular}

Keterangan:

$\langle g\rangle=$ rata-rata gain ternormalisasi

$\langle\mathrm{Sf}\rangle=$ rata-rata nilaitesakhir (post-test)

$\langle\mathrm{Si}\rangle=$ rata-rata nilaitesawal (pre-test)

Smax $=$ Nilaiskormaksimal

$$
\begin{aligned}
(\mathrm{g}) & =\frac{(8,67-6,67)}{(10-6,67)} \\
& =0,45
\end{aligned}
$$


Hasil per Hasil perhitungan diinterpretasikan dengan menggunakan indeks gain $<\mathrm{g}>$, ditunjukkan pada Tabel 10 berikut ini:

Tabel 10.Nilai Indeks Gain Ternormalisasi dan Klasifikasinya

\begin{tabular}{|c|c|}
\hline Indeks Gain Ternormalisasi & Klasifikasi \\
\hline $\mathbf{( g )} \geq \mathbf{0 , 7 0}$ & Tinggi \\
\hline $\mathbf{0 , 3 0} \leq \mathbf{0 , 7 0}$ & Sedang \\
\hline$\leq \mathbf{0 , 3 0}$ & Rendah \\
\hline
\end{tabular}

Dengan melihat hasil perhitungan dengan melihat tabel Indek gain maka disimpulkan bahwa hasil uji efektifitas pengembangan nilai karakter mendapatkan nilai 0,45 terletak pada interval $0,30 \leq 0,70$ dengan klasifikasi sedang, dengan kata lain uji efektivitas dikatakan efektif.

Berdasarkan uji validitas dan reliabilitas menggunakan bantuan Microsoft Excell 2007, diperoleh hasil sebagai berikut; (a) uji validitas dan reliabilitas instrumen karakter dapat diketahui bahwa seluruh item memiliki nilai korelasi $r$ lebih besar dari $r$ tabel $(0,514)$. Dengan demiikian dapat disimpulkan bahwa item 1 sampai dengan 10 dapat dikatakan valid. Dan dapat diketahui bahwa nilai Cronbach's Alpha diperoleh sebesar 0,914 . Nilai tersebut $>0,6$. Dengan demiikian dapat disimpulkan bahwa item 1 sampai dengan 10 dapat dikatakan reliabel, (b) uji validitas dan reliabilitas instrumen guru, dapat diketahui bahwa seluruh item memiliki nilai korelasi $r$ lebih besar dari $r$ tabel $(0,878)$. Dengan demiikian dapat disimpulkan bahwa item 1 sampai dengan 22 dapat dikatakan valid, dan dapat diketahui bahwa nilai Cronbach's Alpha diperoleh sebesar 1,00 . Nilai tersebut $>0,6$. Dengan demiikian dapat disimpulkan bahwa item 1 sampai dengan 22 dapat dikatakan reliabel, dan (c) uji validitas dan reliabilitas instrumen siswa, dapat diketahui bahwa seluruh item memiliki nilai korelasi $r$ lebih besar dari $r$ tabel $(0,173)$. Dengan demiikian dapat disimpulkan bahwa item 1 sampai dengan 16 dapat dikatakan valid, dan dapat diketahui bahwa nilai Cronbach's Alpha diperoleh sebesar 0,614. Nilai tersebut $>0,6$. Dengan demiikian dapat disimpulkan bahwa item 1 sampai dengan 16 dapat dikatakan reliabel

\section{SIMPULAN}

Produk akhir penelitian ini menghasilkan buku pedoman peraturan dan DVD pembelajaran model permainan tradisional untuk membangun karakter pada siswa SD kelas atas. Hasil semua penelitian berdasarkan perhitungan normatif berkategori baik, berkategori baik artinya model yang dikembangkan dapat mengembangkan karakter siswa, dan model yang dikembangkan sesuai dengan karakteristik dan pembelajaran penjas. Model yang digunakan juga mudah digunakan guru dalam pembelajaran penjas. Uji Efektifitas dengan melihat tabel gain semua penilaian berkatagori sedang, data dalam uji efektifitas berdistribusi normal dan uji t pretest dan postest mengalami perubahan yang signifikan.

Pembahasan dan simpulan yang telah dipaparkan di atas, dapat dirumuskan beberapa saran penting menyangkut proses penelitian dan pengembangan ini, antara lain: (a) Saran pemanfaatan berdasarkan penelitian pengembangan yaitu agar model yang dikembangkan dapat digunakan guru penjasorkes SD sebagai salah satu bentuk pembelajaran permainan sederhana pada siswa kelas atas. (b) diseminasi hasil penelitian ini dapat dilakukan melalui seminar, ataupun penelitian baik penelitian tindakan kelas. (c) untuk pengembangan lebih lanjut perlu dilakukan penelitian yang melibatkan subjek coba yang lebih besar dan cakupan lokasi uji coba yang luas, menyeluruh, dan merata. Pengembangan lebih lanjut dapat juga dilakukan dengan penelitian yang serupa hanya yang berbeda sasaran subjek coba diperuntukkan bagi anak sekolah dasar kelas bawah. 


\section{DAFTAR PUSTAKA}

Husna, A. M. (2009). 100+ permainan tradisional indonesia. Yogyakarta: Andi Offlet.

Isti Dwi P.W \& Touvan J.S. (2013). Pendidikan karakter melalui pendidikan jasmani. Bandung: CV. Bintang WarliArtika.

Kesuma, D. (2011). Pendidikan karakter. Bandung: PT Remaja Rosdakarya Offset.

Linggar, S. (2010). Ayo lestarikan permainan tradisional. Jakarta: CV Karya Mandiri Nusantara.

Lusiana, Erlita. (2012). Membangun pemahaman karakter kejujuran melalui permainan tradisional jawa pada anak usia dini

Rich, Edward. Dkk. (2008). Megaskills. Canada: Former Senator and author of The New American Story.

Suharjana., Fredericus. (2011). Pengembangan pembelajaran senam melalui bermain di sekolah dasar. Jurnal Pendidikan Jasmani Indonesia Volume 8. Nomer 1, 216.

Sridadi. (2009). Modifikasi permainan softball untuk siswa sekolah dasar. Jurnal Pendidikan Jasmani Indonesia Volume 6, 1, 46-54.

Yuliani, N. Sujiono \& Sujiono, Bambang. (2010). Bermain kreatif berbasis kecerdasan jamak. Jakarta: PT. Indeks 